\title{
Eye disorders in patients with multiple sclerosis: natural history and management
}

This article was published in the following Dove Press journal:

Clinical Ophthalmology

2 December 2010

Number of times this article has been viewed

\section{Jennifer Graves \\ Laura J Balcer}

Department of Neurology, University of Pennsylvania, Philadelphia, PA, USA

Correspondence: Laura J Balcer Department of Neurology, 3 E Gates, 3400 Spruce Street, Philadelphia, PA 19104, USA

Tel +l 2I5 3498072

$\mathrm{Fax}+\mathrm{I} 2153495579$

Email lbalcer@mail.med.upenn.edu
Abstract: Multiple sclerosis (MS) is a demyelinating disease of the central nervous system and leading cause of disability in young adults. Vision impairment is a common component of disability for this population of patients. Injury to the optic nerve, brainstem, and cerebellum leads to characteristic syndromes affecting both the afferent and efferent visual pathways. The objective of this review is to summarize the spectrum of eye disorders in patients with MS, their natural history, and current strategies for diagnosis and management. We emphasize the most common disorders including optic neuritis and internuclear ophthalmoparesis and include new techniques, such as optical coherence tomography, which promise to better our understanding of MS and its effects on the visual system.

Keywords: optic neuritis, vision, internuclear ophthalmoparesis, nystagmus, diplopia

\section{Introduction}

Approximately 300,000 individuals in the United States are affected by multiple sclerosis (MS) ${ }^{1-4}$ The national economic burden of this disease has been estimated to be US $\$ 6.8$ billion yearly and the total lifetime cost per case to be US $\$ 2.2$ million. ${ }^{5}$ Visual dysfunction is frequent and often irreversible. Afferent pregeniculate visual pathways (retina, optic nerves, chiasm, and tracts) are targets of inflammation, demyelination, and axonal degeneration (Panel 1). Nearly half of the MS patients develop optic neuritis $(\mathrm{ON}){ }^{6}$ It is the heralding event in $15 \%-20 \%$ of patients. ${ }^{6}$ However, patients without a clinical history of $\mathrm{ON}$ also exhibit poor visual function, including worse scores on low-contrast acuity and color-sensitivity testing, when compared with age-matched controls. ${ }^{7,8}$ With the advent of newer technology, structural information about optic nerve disease is attainable, and MS patients with and without a history of $\mathrm{ON}$ demonstrate loss of axons in the retinal nerve fiber layer (RNFL) ${ }^{9-12}$

Injury is also common in the brainstem and cerebellum, generating efferent pathway deficits. Common ocular motor findings include internuclear ophthalmoparesis (INO), saccadic dysmetria, and nystagmus. Also found are skew deviation, abnormalities of smooth pursuit, and various nuclear and fascicular lesions. After careful bedside neuroophthalmologic examination, these disorders can be readily identified. Corresponding lesions are often visible on magnetic resonance imaging (MRI).

The principal objective of this review is to provide a framework for understanding both the afferent and efferent visual disorders in MS and outline the current strategies for management of these syndromes. 
Panel I Afferent neuro-ophthalmologic disorders in MS

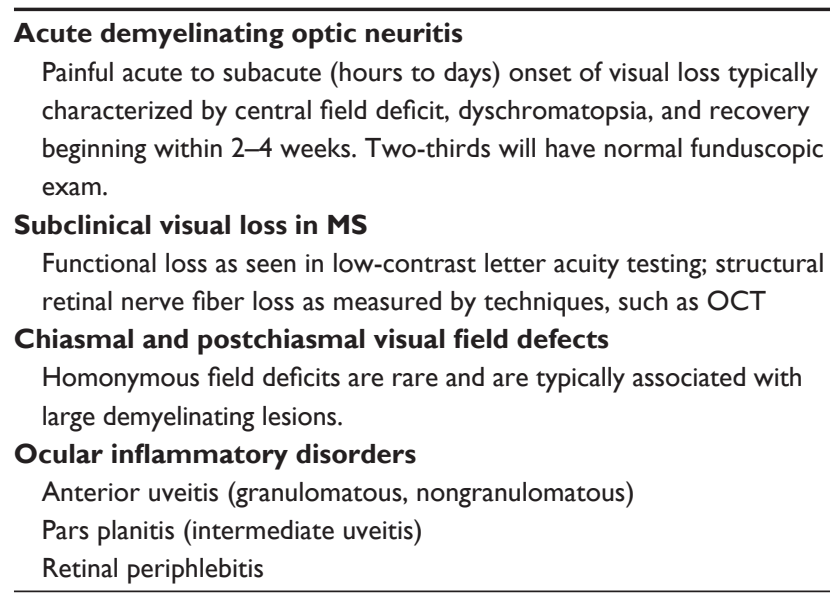

\section{The afferent visual system in MS Acute demyelinating $\mathrm{ON}$ \\ Clinical presentation}

$\mathrm{ON}$ refers to the inflammation of the optic nerve. Although the differential diagnosis is broad and includes infectious, ischemic, and autoimmune disorders, the most common form, acute demyelinating $\mathrm{ON}$, is best known for its association with MS. It is more prevalent in young patients and in women. ${ }^{13}$ The Optic Neuritis Treatment Trial (ONTT), the largest and most comprehensive study of this disease, followed an initial cohort of 457 patients for 10 years and provided important data on the natural history and visual outcomes of $\mathrm{ON}$ cases and the effects of high-dose steroids. ${ }^{14-19}$

The diagnosis of ON is primarily clinical based on history and examination..$^{20}$ Patients report acute to subacute vision loss, color desaturation (in particular red color), and in the ONTT, $92 \%$ of patients reported pain with eye movements. ${ }^{13}$ Vision loss is typically monocular and progresses over hours to days; worsening beyond 1-2 weeks is atypical and suggestive of other causes of optic neuropathy. ${ }^{15}$ Similarly, it is expected that some recovery will occur within 1 month of symptom onset. Failure to see improvement in this time frame, the presence of no light perception at onset, and lack of eye pain suggest other diagnoses and are associated with lower risk for developing MS. ${ }^{21,22} \mathrm{~A}$ single episode of ON with no history of other ophthalmologic or neurological events can be described as a clinically isolated syndrome (CIS).

\section{Afferent neuro-ophthalmologic examination}

The afferent eye examination begins with acuity testing. Prescription lenses or pinhole correction are used to correct refractive error. Distance, near card, or both are measured for normal contrast levels. As discussed below, further evaluation with low-contrast charts may reveal more subtle visual dysfunction. Visual fields are tested to confrontation for each eye separately and together. Static and dynamic finger recognition may be helpful. Red-green color desaturation is a common feature in ON and may be detected by the patient's description of "washed out" appearance of red objects; however, it is usually formally tested with Ishihara pseudoisochromatic plates or Farnsworth-Munsell 100 hue test, as done in the ONTT.

Pupils are evaluated for shape, position, anisocoria, and reactivity. In addition, detection of a relative afferent pupillary defect (RAPD) is suggestive of an optic neuropathy. Absence of an RAPD in the setting of visual loss may reflect retinal disease or bilateral optic nerve disease. Funduscopic examination reveals normal appearing discs in most of the cases; these patients are said to have retrobulbar ON. In the ONTT, optic disc swelling was present in $35.3 \%$ of the patients (Figure 1). ${ }^{13}$ Marked swelling, retinal hemorrhages,

A

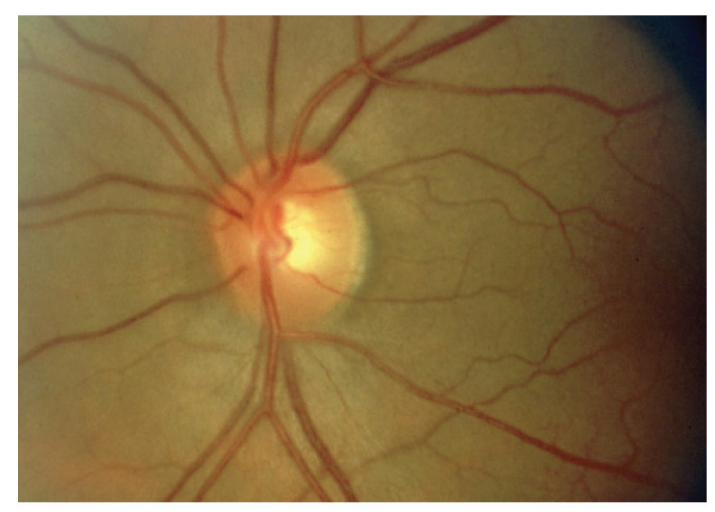

B

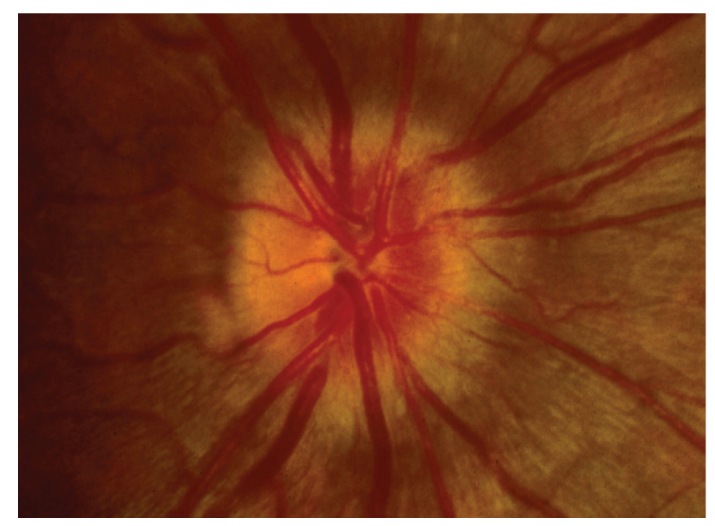

Figure I The optic disc in acute demyelinating optic neuritis. Most patients have retrobulbar optic neuritis, and the optic disc appears normal $(\mathbf{A})$. In one-third of the patients, disc swelling is present and is typically diffuse and mild (B)..$^{13}$

Copyright (c) 2006, Massachusetts Medical Society. Adapted with permission from Balcer LJ. Optic neuritis. N EnglJ Med. 2006;354:1273-1280. Liu GT, Volpe NJ, Galetta SL. Neuro-Opthalmology: Diagnosis and Management. Ist ed. Philadelphia, PA: WB Saunders Company; 200I. 
and exudates are atypical, which suggest an alternative diagnosis and predict a lower risk of developing MS..$^{21,22}$

\section{Differential diagnosis}

Acute demyelinating ON must be differentiated from other causes of optic neuropathy. As described earlier, lack of eye pain, severe initial vision loss, marked swelling, and retinal hemorrhages may indicate an alternative diagnosis of anterior ischemic optic neuropathy (AION, Table 1). ${ }^{23}$ AION usually occurs in older patients. Compared with ON, the vision loss is often sudden in onset, altitudinal, and more likely to persist, with longer time to recovery. ${ }^{24}$ When vision loss progresses beyond 10-14 days, Leber hereditary optic neuropathy, a mitochondrial disorder leading to the degeneration of the optic nerve, may need to be considered, along with compressive optic neuropathy.

Bilateral ON or ON coupled with longitudinally extensive transverse myelitis (LETM) is suggestive of neuromyelitis optica (NMO), a disorder associated with aquaporin-4 (a water channel present in glial cells) antibodies. ${ }^{25-27}$ Testing for NMO-IgG should be considered in those patients with the features described earlier, recurrent ON, or brain MRIs atypical for MS. ${ }^{27}$ In 1 study, in which patients were identified by having been tested for NMO-IgG, seropositivity was shown to be $76 \%$ sensitive and $94 \%$ specific for $\mathrm{NMO} .{ }^{28} \mathrm{~A}$ prospective study of 114 patients with $\mathrm{ON}$ in various clinical contexts demonstrated that $56 \%$ of those with clinical NMO had positive serum antibodies..$^{29}$ In noncausasions or while using different detection methods, the sensitivity of testing may vary, but specificity appears

Table I Clinical features and primary differential diagnosis of acute demyelinating optic neuritis

\begin{tabular}{|c|c|c|}
\hline & $\begin{array}{l}\text { Acute demyelinating } \\
\text { optic neuritis }\end{array}$ & $\begin{array}{l}\text { Anterior ischemic } \\
\text { optic neuropathy }\end{array}$ \\
\hline Age, y & $20-50$ & $>50$ \\
\hline Pain & $\begin{array}{l}92 \% \text {, exacerbated by eye } \\
\text { movements }^{\mathrm{a}}\end{array}$ & Uncommon \\
\hline Onset & $\begin{array}{l}\text { Progression over hours } \\
\text { to days }\end{array}$ & $\begin{array}{l}\text { Sudden onset, often } \\
\text { recognized upon } \\
\text { awakening }\end{array}$ \\
\hline Disc swelling & $\begin{array}{l}\text { Present in only one-third } \\
\text { of patients, remainder are } \\
\text { retrobulbar }\end{array}$ & $\begin{array}{l}\text { Common, sectoral, } \\
\text { often with hemorrhages }\end{array}$ \\
\hline Field defect & $\begin{array}{l}\text { Typically central, but } \\
\text { variable }\end{array}$ & Typically altitudinal \\
\hline Recovery & $\begin{array}{l}\text { Begins within } 2-4 \text { weeks, } \\
\text { overall good prognosis }\end{array}$ & $\begin{array}{l}\text { Over months, in } \\
\text { approximately } 40 \% \text { b }\end{array}$ \\
\hline
\end{tabular}

Notes: aFrom the optic neuritis treatment trial (ONTT); ${ }^{13}$ blschemic optic neuropathy decompression trial. ${ }^{24}$

Copyright (c) 2006, Massachusetts Medical Society. Adapted with permission from Balcer LJ. Optic neuritis. N Engl J Med. 2006;354:1273-1280. to be robust across multiple testing contexts. ${ }^{30,31}$ The revised criteria for diagnosing NMO are the presence of 2 of the following 3 findings - LETM (defined as $\geq 3$ vertebral segments), onset brain MRI nondiagnostic for MS, or NMO-IgG seropositivity. ${ }^{28}$ Antibody positivity may help determine the likelihood of recurrent disease and guide the decision to treat with immunosuppression following an episode of ON or recurrent ON. ${ }^{30,32-34}$ Although large treatment trial data are not available, therapies studied and shown to have beneficial effects include plasma exchange, rituximab, and azothiaprine..$^{35-39}$

Other causes of inflammatory or toxic metabolic optic neuropathy may mimic acute demyelinating disease. ${ }^{20}$ Depending on the clinical assessment and presence of atypical features, serologic or cerebrospinal fluid (CSF) testing for sarcoidosis, systemic lupus and other vasculitides, thyroid disease, syphilis, nutritional deficiencies, Lyme disease, Bartonella hensalae infection (cat scratch neuroretinitis), and paraneoplastic disorders may be warranted. Consideration should also be given to the newly recognized entity, chronic relapsing inflammatory optic neuropathy (CRION), a granulomatous optic neuropathy. ${ }^{40}$

\section{Vision testing}

Although the diagnosis of $\mathrm{ON}$ is made clinically, additional testing of vision function can be used to support the diagnosis and further characterize the patient's deficits. In the ONTT, visual outcome measures included formal visual field testing (Humphrey $30-2^{\circledR}$ program) and contrast sensitivity (PelliRobson ${ }^{\circledR}$ chart). Visual field deficits were found in $97.5 \%$ of patients. ${ }^{13}$ Central scotomas were common but other patterns, including diffuse and focal defects, were seen. Contrastsensitivity (minimum contrast level at which patients can see letter of single large size) abnormalities were seen in $98.2 \%$ of patients. ${ }^{41}$

Low-contrast letter acuity charts, which have a format similar to Early Treatment Diabetic Retinopathy Study (ETDRS) charts with light gray letters of progressively smaller size with varying contrast on white background, have also been used to detect visual dysfunction in patients with ON and MS..$^{-9,42}$ Abnormalities can be detected even in those patients with 20/20 vision measured by standard Snellen ${ }^{\circledR}$ charts.

Visual evoked potentials (VEPs) can be helpful in providing data to support the diagnosis of acute demyelinating disease, ON, or MS. Prolonged latencies are consistent with demyelinating disease and are present in over two-thirds of patients with ON..$^{43-45}$ Multifocal VEPs can be more sensitive 
and specific; they can be useful in distinguishing optic nerve and retinal disease or for detecting subclinical dysfunction, but are not widely available for clinical use. .3,46,47 $^{4}$

\section{Magnetic resonance imaging}

MRI of the optic nerves is abnormal in approximately $90 \%$ of clinical cases (Figure 2B) and can be helpful in diagnosis under certain clinical circumstances, as in differentiating acute demyelinating ON and AION. ${ }^{48}$ Gadolinium enhancement is frequent and has been shown to be associated with clinical findings such as decreased acuity, RAPD, and abnormal VEPs. ${ }^{49}$

A

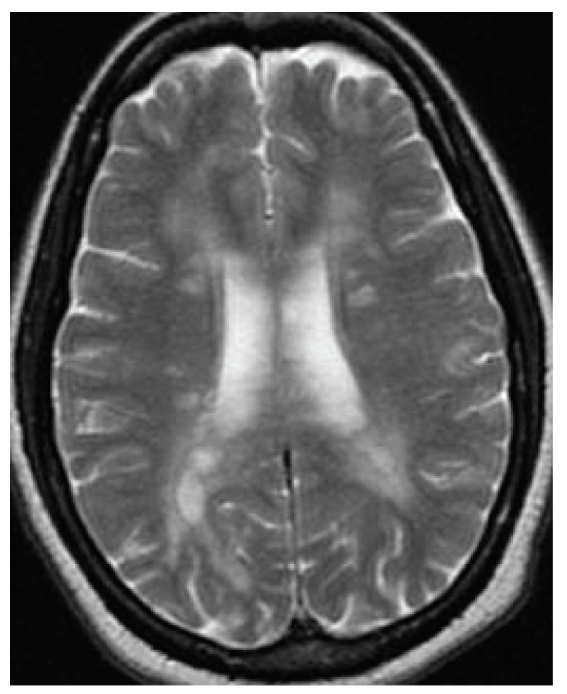

B

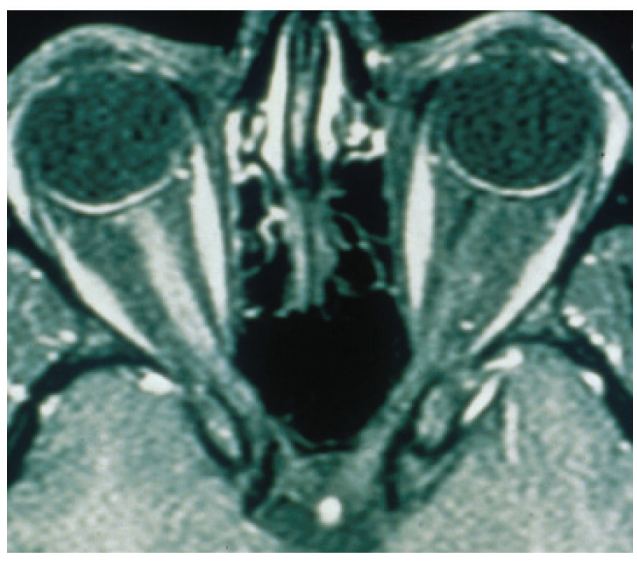

Figure 2 Magnetic resonance imaging (MRI) in multiple sclerosis (MS) and optic neuritis (ON). Multiple periventricular $\mathrm{T}_{2}$-hyperintense lesions are shown in a $\mathrm{T}_{2}$-weighted axial image of the brain in a patient with MS (A). $\mathrm{T}_{1}$-weighted gadoliniumenhanced axial image of the orbits demonstrates diffuse enhancement of the right optic nerve in a patient with acute demyelinating ON (B).

Copyright (c) 2006, Massachusetts Medical Society. Adapted with permission from Balcer LJ. Optic neuritis. N Engl J Med. 2006;354:1273-1280. Liu GT, Volpe NJ, Galetta SL. Neuro-Opthalmology: Diagnosis and Management. Ist ed. Philadelphia, PA: WB Saunders Company; 200 I.
It is recommended in every patient to pursue brain MRI (Figure 2A), as the presence of periventricular white matter lesions is associated with higher risk in first event cases of developing a second demyelinating event consistent with MS and may warrant early treatment as discussed below. In the ONTT follow-up at 10 years, $56 \%$ of ON patients with 1 or more $\mathrm{T}_{2}$ lesions on MRI had developed MS compared with $22 \%$ of those with normal scans. ${ }^{21}$ Brain lesions are common and are seen in $50 \%-70 \%$ of patients. ${ }^{50,51}$ In 1 study, spinal cord $\mathrm{T}_{2}$ lesions were seen in $27 \%$ of patients. ${ }^{50}$

Artifacts can limit MRI studies in ON and MS. Fat- and CSF-suppressed imaging, diffusion tensor and magnetization transfer imaging, and spectral presaturation inversion recovery-fluid-attenuated inversion recovery (SPIR-FLAIR) imaging promise more sensitivity and detailed structural information of not only ON but also of long-term atrophy and changes in the optic nerve. ${ }^{49,52,53}$

\section{Optical coherence tomography}

New advances in optical coherence tomography (OCT) have also allowed for direct structural assessment of axonal loss associated with ON. ${ }^{10,54} \mathrm{OCT}$, an optical analog of ultrasound B-mode imaging, provides cross-sectional or 3-dimensional images of the internal retinal structure. ${ }^{11,55,56}$ Measurements of the thickness of RNFL, ganglion cell axons, can be readily obtained. Studies have demonstrated RNFL thinning in eyes with a history of ON; in 1 study, reductions in RNFL thickness occurred in $74 \%$ of patients, typically within 3-6 months of the acute episode. ${ }^{57,58}$ Decreases in RNFL thickness have been correlated with measures of visual dysfunction, such as low-contrast acuity and with brain atrophy on MRI scans. ${ }^{9,59-61}$ Although currently used primarily in the research setting, longitudinal OCT measurements have the potential to elucidate the natural history of axonal loss in ON and MS patients, as well as to provide a biomarker for the neuroprotective effects of current and future therapies. Studies of other methods for measuring the axonal layer, including scanning laser polarimetry, may also generate structural biomarkers for studying progression in MS. ${ }^{10,12}$

\section{Natural history}

In cases of typical $\mathrm{ON}$, visual recovery begins within 2-3 weeks. The natural history of the disease is likely best described by the course of patients in the placebo arm of the ONTT. With median baseline acuity of affected eyes measured to be $20 / 60$, vision improved to $20 / 25$ by day 15 and to $20 / 20$ at 1 month of follow-up. ${ }^{62}$ In the 10 -year follow-up 
of 319 patients from the ONTT, visual acuity (treated and untreated) in the affected eye was equal to or better than $20 / 20$ in $74 \%, 20 / 25$ to $20 / 40$ in $18 \%, 20 / 50$ to $20 / 200$ in $5 \%$, and $20 / 200$ in $3 \% .{ }^{19}$ However, even with recovery of visual acuity, self-reported visual functioning as measured by the National Eye Institute Visual Functioning Questionnaire (NEI-VFQ-25) can remain affected. Evidence of optic atrophy can be seen weeks following the acute event. ${ }^{19}$ Contrast sensitivity and visual fields were abnormal in 33\% and $27 \%$ of affected eyes, respectively (compared with $98.2 \%$ and $97.5 \%$ at baseline as mentioned earlier), in the 10 -year follow-up of the ONTT. ${ }^{19}$

Of interest in the natural history of $\mathrm{ON}$ is the rate of recurrent $\mathrm{ON}$ and the development of MS. Recurrence of $\mathrm{ON}$ in the 10-year follow-up of the ONTT was $31 \%$ for the placebo group (48\% for those with MS and 24\% of those without MS). ${ }^{19}$ Risk for developing MS in the treatment and placebo arms followed for 10-13 years was $38 \% .^{22}$ As discussed earlier, the risk was higher for those with brain MRI lesions and lower (close to zero) for those patients with atypical clinical features, such as severe optic disc swelling, peripapillary hemorrhages, and absence of eye pain. ${ }^{21,22}$

\section{Treatment}

\section{Short-term therapy with corticosteroids}

High-dose intravenous (IV) methylprednisolone hastens recovery of visual acuity and other visual function tests over a 2-year follow-up, but does not affect the long-term visual outcomes of patients with $\mathrm{ON}$ or their 10-year risk of developing MS. In the ONTT, patients were randomized within 8 days of onset of symptoms to 1 of 3 treatment groups: (1) IV methylprednisolone $250 \mathrm{mg}$ every 6 hours for 3 days, followed by oral prednisone $1 \mathrm{mg} / \mathrm{kg} / \mathrm{d}$ for 11 days with a 4-day taper, (2) oral prednisone $1 \mathrm{mg} / \mathrm{kg} / \mathrm{d}$ for 14 days followed by 4-day taper, or (3) oral placebo. ${ }^{15}$ Treatment with IV steroids was associated with a more rapid recovery of visual field deficits and contrast sensitivity, particularly within the first 15 days, and differences in recovery for these parameters remained significant at 6 -month follow-up. ${ }^{15}$ For visual acuity, there was no difference between treatment groups at 6 months. At 1 year of follow-up, there were no significant differences for any measure of visual function. ${ }^{17}$

The rate of development of MS, then defined as a second clinical demyelinating event, after 2 years of follow-up was $7.5 \%$ in the IV methylprednisolone group, $14.7 \%$ in the oral prednisone group, and $16.7 \%$ in the placebo arm. These data suggested an early protective effect in the development of clinically definite MS (CDMS). ${ }^{63}$ However, this effect did not persist in further follow-up evaluations.

Similar studies have also shown potential early but no significant long-term benefits for corticosteroid therapy in ON. A randomized study in Japan compared IV methylprednisolone with oral methylcobalamine and demonstrated quicker recovery of visual acuity, visual fields, contrast sensitivity, and color vision but no long-term effect on visual outcomes. ${ }^{64} \mathrm{~A}$ meta-analysis of 12 randomized controlled trials in $\mathrm{ON}$ and MS also showed that corticosteroid use appeared to hasten recovery within 1 month of symptom onset, but significant benefits were not observed after 1 year of follow-up. ${ }^{65}$

Another outcome of the ONTT was an increased rate of recurrent $\mathrm{ON}$ in the oral prednisone group compared with the IV methylprednisolone and the placebo groups. At 5 years of follow-up, the oral prednisone group had a rate of recurrence of $41 \%$ compared with $25 \%$ for the IV methylprednisolone and placebo groups. ${ }^{66}$ This increased risk did not persist at 10 years of follow-up. ${ }^{19}$ This result has discouraged the use of oral prednisone for the acute treatment of ON. Higher doses of oral steroids (500 mg methylprednisolone daily for 5 days) in a small prospective trial did not show increased risk of recurrent $\mathrm{ON}$ within 1 year. ${ }^{67}$

\section{Long-term therapy with immunomodulatory agents}

In patients with a first event of $\mathrm{ON}$, early treatment with disease-modifying therapy (Table 2), interferon, or glatiramer acetate may delay the onset of a second clinical demyelinating event and the development of new $\mathrm{T}_{2}$ lesions or gadolinium enhancement. Three randomized trials of patients with first demyelinating events, including $\mathrm{ON}$, have shown benefit for early treatment with interferon $\beta$-1a and interferon $\beta$ - 1 b. An additional trial recently showed similar results for glatiramer acetate.

The Controlled High-Risk Subjects Avonex Multiple Sclerosis Prevention Study (CHAMPS) was a doubleblinded, randomized clinical trial that included 383 patients with acute $\mathrm{ON}$ or other first demyelinating event. ${ }^{68}$ The patients were considered high risk for MS based on MRI criteria of 2 or more white matter lesions. All patients received $1 \mathrm{~g}$ of IV methylprednisolone daily followed by an oral prednisone taper. They were then randomly assigned within 27 days to receive weekly injections of $30 \mu \mathrm{g}$ intramuscular interferon $\beta$-1a $\left(\right.$ Avonex $\left.^{\circledR}\right)$ or placebo injections. The trial was stopped early after a preplanned efficacy analysis. The trial's 2 primary end points, development of CDMS and changes on MRI, demonstrated benefit for interferon 
Table 2 Treatment choices for optic neuritis or other first demyelinating event in patients at risk for multiple sclerosis

\begin{tabular}{lll}
\hline Trial evidence & Medication (standard dosage) & $\begin{array}{l}\text { Contraindications/potential Potential benefits } \\
\text { side effects }\end{array}$ \\
\hline
\end{tabular}

\section{Short-term therapy}

Optic neuritis treatment trial (ONTT, $\mathrm{n}=457$ )

\section{Long-term therapy}

Controlled high-risk subjects avonex MS prevention study (CHAMPS, $n=383$ )

Early treatment of MS study (ETOMS, $\mathrm{n}=308$ )

Betaferon/Betaseron in newly emerging MS for initial treatment (BENEFIT, $\mathrm{n}=468$ )

Effect of glatiramer acetate on conversion to clinically definite multiple sclerosis (PreCISe, $\mathrm{n}=48 \mathrm{I}$ )
Intravenous methylprednisolone $(250 \mathrm{mg}$ every $6 \mathrm{~h}$ for $3 \mathrm{~d})+$ oral taper

Interferon $\beta$-Ia (Avonex, $30 \mu \mathrm{g}$ intramuscularly weekly)

Interferon $\beta$ - Ia (Rebif, $22 \mu \mathrm{g}$ subcutaneously weekly) ${ }^{2}$

Interferon $\beta$-Ib (Betaseron, $250 \mu \mathrm{g}$ subcutaneously every other day)

Glatiramer acetate (Copaxone, $20 \mathrm{mg}$ subcutaneously daily)
Contraindications: systemic infection, immune deficiency, severe hypertension, or diabetes mellitus; Side effects: insomnia, mood disturbance, gastric irritation, hyperglycemia, hypertension

Contraindications: pregnancy category $\mathrm{C}$, hypersensitivity to interferon $\beta$ or human albumin; Side effects: flu-like symptoms (fever, myalgias), depression, anemia, hepatic dysfunction Contraindications: pregnancy category $C$, hypersensitivity to interferon $\beta$ or human albumin; Side effects: flu-like symptoms (fever, myalgias), depression, anemia, hepatic dysfunction Contraindications: pregnancy category $\mathrm{C}$, hypersensitivity to interferon $\beta$ or human albumin; Side effects: flu-like symptoms (fever, myalgias), depression, anemia, hepatic dysfunction Contraindications: pregnancy category B; Side effects: injection site reaction, rash, vasodilation, dyspnea, chest pain
I. Faster recovery of visual function; longterm visual outcome not affected

2. Reduced rate of MS development within the first $2 y$

3. Oral prednisone at dose of $\mathrm{I} \mathrm{mg} / \mathrm{kg}$ may increase the risk of recurrent optic neuritis and should be avoided.

I. Reduction $(44 \%, P=0.02)$ in the $3-y$ risk of developing CDMS

2. Fewer new and enhancing lesions on MRI

I. Lower risk of developing CDMS over 2 y ( $34 \%$ vs $45 \%$ placebo, $P=0.047$ )

2. Decreased annual relapse rate $(0.33$ vs $0.43, P=0.045$ )

3. Fewer lesions on MRI

I. Reduced 2-y risk of developing CDMS by the Poser ( $28 \%$ vs $45 \%$ placebo, $P<0.000 \mathrm{I})$ and McDonald (69\% vs $85 \%$ placebo) criteria

2. Fewer lesions on MRI

I. Decreased risk of developing CDMS compared with placebo by $45 \%$ $(P<0.0005)$

2. Fewer lesions on MRI

Notes: aETOMS used weekly $22 \mu \mathrm{g}$ Rebif, while standard therapy for MS is 22 or $44 \mu \mathrm{g} 3$ times a week.

Adapted with permission from Burkholder et al. ${ }^{157}$

Abbreviations: MS, multiple sclerosis; CDMS, clinically definite multiple sclerosis; MRI, magnetic resonance imaging.

therapy. Patients receiving intramuscular interferon $\beta$-1a had a $44 \%$ reduction in the 3 -year risk of CDMS $(P=0.02)$ and fewer new and enhancing lesions on MRI ${ }^{68}$ In subgroup analyses, the beneficial effect was present for presentations of ON, as well as for brainstem-cerebellar and spinal cord syndromes. ${ }^{69,70}$ The extension study, Controlled High-Risk Avonex Multiple Sclerosis Prevention Study in Ongoing Neurological Surveillance (CHAMPIONS), demonstrated that patients who received the early interferon treatment (those initially randomized to the active treatment group) had persistently lower risk of developing MS at 5 years of follow-up (21\%) compared with those who started therapy once efficacy was established at 2-3 years of follow-up in open-label extension (35\%). ${ }^{71}$

The Early Treatment of Multiple Sclerosis (ETOMS) study also showed that interferon $\beta$-1a reduces risk of developing MS over 2 years after a first demyelinating event. ${ }^{72}$
In this trial, 308 patients were randomized to weekly $22 \mu \mathrm{g}$ subcutaneous interferon $\beta$-1a $\left(\right.$ Rebif $\left.^{\circledR}\right)$ or placebo within 3 months of symptom onset. Over one-third of patients had evidence of 2 or more white matter lesions on MRI at presentation, and most of the patients had received steroids before initiation of injections. Treated patients had a risk of $34 \%$ of developing MS in the 2-year period vs $45 \%$ for controls $(P=0.047)$. Another marker for benefit, the time for $30 \%$ of each cohort to develop MS was 569 days in the interferon group and 252 in the placebo group $(P=0.034)$. Annual relapse rate was also lower in the interferon group, 0.33 vs 0.43 per year $(P=0.045)$, and disease burden by MRI was less.

The third trial, Betaferon/Betaseron in Newly emerging Multiple Sclerosis for Initial Treatment (BENEFIT) looked at another common injectable therapy for MS. ${ }^{73}$ Patients with acute demyelinating events $(487,80$ with $\mathrm{ON})$ were 
randomized to $250 \mu \mathrm{g}$ of subcutaneous interferon $\beta-1 \mathrm{~b}$ $\left(\right.$ Betaseron $^{\circledR}$ ) or placebo. Development of CDMS by the Poser criteria was $28 \%$ in the treatment group vs $45 \%$ in the placebo group $(P<0.0001)$ and by the newer McDonald criteria, including MRI parameters for lesions in time and space, was 69 vs $85 \%$, respectively. ${ }^{73-75}$ Patients on interferon also had significantly fewer lesions on brain MRI.

The effect of glatiramer acetate $\left(\right.$ Copaxone $\left.^{\circledR}\right)$ on the development of second demyelinating events after a CIS was addressed by the PreCISe trial. Patients with CIS and 2 or more $\mathrm{T}_{2}$-weighted brain lesions were assigned to $20 \mathrm{mg}$ subcutaneous glatiramer acetate daily vs placebo for 36 months. ${ }^{76}$ Use of the drug reduced the risk of developing CDMS by $45 \%$ compared with placebo. ${ }^{76}$

\section{Summary}

In patients with $\mathrm{ON}$ and high risk of MS, defined as 2 or more white matter lesions on brain MRI and lack of atypical clinical features, we recommend treatment in the acute setting with IV methylprednisolone followed by disease modifying therapy. Discussion with the patient about his or her risk of MS is important in this setting. Even in those patients without the evidence of other MRI lesions, it is appropriate to follow them with MRI scans for future development of white matter lesions. IV steroids may also be recommended in this group to expedite recovery of visual function.

\section{Visual loss in absence of acute clinical ON}

Even in patients without history of acute clinical ON, MS is associated with visual dysfunction. Low-contrast letter acuity charts have been used to detect clinically subtle visual dysfunction in MS, even among patients with 20/20 or better high-contrast visual acuity and no history of acute ON. ${ }^{7,8}$ Use of low-contrast letter acuity charts and the Pelli-Robson contrast-sensitivity chart can distinguish MS eyes from controls to a degree better than high-contrast visual acuity testing. ${ }^{42}$ OCT studies demonstrate subclinical RNFL thinning in MS eyes, even among those without a history of acute ON. While the greatest reductions in RNFL thickness are seen in eyes with history of ON, non-ON eyes of MS patients show decreases in RNFL thickness compared with disease-free controls. ${ }^{9,77}$ RNFL thinning in MS has been shown to correlate with MRI measures of lesion volume and normalized brain volumes, for example, $\mathrm{T}_{1}$ - and $\mathrm{T}_{2}$-lesion volume and normalized gray matter volume (relationship to normalized white matter volume is less clear) and with losses of low-contrast acuity over time. ${ }^{60,78-80}$

\section{Other afferent disorders in MS}

Disorders of the afferent visual system in MS may encompass structures beyond the optic nerve, including chiasmal and postchiasmal visual field deficits, or may involve diseases of ocular inflammation (Panel 1). Symptomatic homonymous field deficits are rare, but with screening, unrecognized defects may be found ${ }^{81}$ In the ONTT, $13.2 \%$ of patients had evidence of a chiasmal or retrochiasmal deficit upon serial screening, $5.1 \%$ of which were bitemporal and $8.9 \%$ were homonymous. ${ }^{82}$ In 1 study of 18 patients with retrochiasmal field deficits, lesions were found on MRI in the posterior optic radiations, the optic tract, lateral geniculate nucleus, and the posterior limb of the internal capsule; all of the lesions were unusually large, a characteristic feature considered necessary to observe a homonymous deficit in this disease. ${ }^{83}$

Ocular inflammation may be seen in patients with MS. Types include anterior uveitis, pars planitis (intermediate uveitis), and retinal periphlebitis. Uveitis is 10 times more common in MS patients than in the general population, but it is a rare complication and often unrecognized. ${ }^{84,85}$ In a study of $16 \mathrm{MS}$ patients with uveitis, Zein et al ${ }^{86}$ reported that $94 \%$ of those cases were bilateral and $81 \%$ were pars planitis. Half of the cases were previously diagnosed with MS; in $25 \%$ of the cases, the diagnosis of uveitis preceded the diagnosis of MS; and in 19\% of the cases, the diagnoses were made concomitantly. ${ }^{86}$

Anterior uveitis, including granulomatous and nongranulomatous forms, arises uncommonly in patients with known MS, but may manifest before diagnosis. ${ }^{85}$ In cases of granulomatous disease, other etiologies must be excluded, including sarcoidosis, tuberculosis, syphilis, Lyme disease, rheumatologic disorders, Behcet's disease, and Vogt-Koyanagi-Harada syndrome. Despite the rarity of isolated anterior uveitis in MS, it is worth considering that the agents used in other inflammatory processes, such as tumor necrosis factor $\alpha$, may be ineffective or detrimental in demyelinating disease. ${ }^{87-89}$

Pars planitis, an idiopathic form of intermediate uveitis, is characterized by intravitreal inflammation and pars plana and peripheral retinal exudates. ${ }^{90}$ It may have no symptoms or be associated with vision loss from complications, including cataracts, epiretinal membrane formation, or macular edema. In a prospective study of 21 patients with pars planitis, $47.6 \%$ were found to have demyelinating lesions on MRI, and relapsing remitting MS was diagnosed in 
$33.3 \% .^{90}$ Another small study found MS in $16 \%$ of patients with pars planitis and found an association between human leukocyte antigen-DR15 (HLA-DR15) and this form of uveitis (odds ratio $[\mathrm{OR}]=2.86 ; 95 \%$ confidence interval $[\mathrm{CI}]$, 1.42-5.78, $P=0.004) .{ }^{91}$ The latter association between pars planitis and HLA-DR2 allelic subtypes has been observed by other groups as well. ${ }^{92,93}$ Overall visual prognosis is generally good with most affected eyes retaining better than 20/40 visual acuity. ${ }^{90,91}$ Treatment options include steroids, nonsteroidal anti-inflammatory agents, immunosuppressant therapy, cryotherapy, or vitrectomy. ${ }^{90}$ In pars planitis patients not previously diagnosed with MS, MRI studies should be considered to rule out demyelinating disease.

Cuffing of retinal veins by inflammatory cells causing whitish exudates, or retinal periphlebitis, is found in $5 \%-36 \%$ of patients with MS. ${ }^{94-97}$ Its presence is thought to be more common in active stages of the disease and its pathogenesis may share commonalities with perivenular inflammation in typical MS plaques. ${ }^{95,96,98,99}$ Retinal periphlebitis in MS is typically mild and may not have any clinical manifestations; more severe cases may be seen in disorders such as sarcoid, syphilis, toxoplasmosis, Eale disease, and idiopathic uveitis. ${ }^{100}$

\section{The efferent visual system in MS}

Discrete lesions in the ocular motor pathway result in classic efferent syndromes (Table 3 ). The most common of these are INO, saccadic dysmetria, nystagmus, and suppression of the vestibulo-ocular reflex (VOR). ${ }^{101,102}$ MRI studies, particularly proton density and $\mathrm{T}_{2}$ images, often show these lesions in the corresponding areas of the brainstem and cerebellum. ${ }^{103}$

\section{The ocular motor examination}

Careful bedside examination can reveal the common efferent disorders associated with MS. ${ }^{104}$ Components of the examination should include assessment of ocular alignment and motility. Alignment in the primary and the cardinal directions of gaze should be evaluated, and the presence of tropias, phorias, and head tilt determined. Ductions (monocular motility) and versions (binocular motility) as well as Maddox rod measurements or other assessment of diplopia should be performed. Saccades, brief eye movements from one point of fixation to another, should be assessed for latency, velocity, and accuracy and may reveal INO and ocular dysmetria due to cerebellar dysfunction, nystagmus, or gaze palsy. Smooth pursuit can be affected by inattention or broken into saccadic movements. Saccadic intrusions visible by external or funduscopic examination are also seen in MS and include square-wave jerks, oscillations, and ocular flutter or opsoclonus. Various types of nystagmus and vestibular disorders are often observed, with the most common types summarized below. Evaluations, such as observation during eye movements, VOR testing, and head thrust, can help distinguish between the neuroanatomic possibilities.

\section{Internuclear ophthalmoparesis}

INO, characterized by limited or slow adduction of the ipsilateral eye on horizontal saccadic eye movements and usually accompanied by horizontal nystagmus in the contralateral eye, INO is commonly associated with MS, and when seen in young undiagnosed patients, an INO should prompt a workup for demyelinating disease. ${ }^{102,105-107}$ Lesions of the medial longitudinal fasciculus (MLF), located in the dorsomedial pontine or midbrain tegmentum, cause INO. In a study of 58 patients with MS and INO, all had evidence of lesions in the MLF by proton density imaging. ${ }^{103}$ Etiologies of INO in a retrospective study of 65 patients included vascular (36.9\%), MS (32.3\%), and infectious disease (13.8\%). ${ }^{105}$ In half of these patients, the INO persisted after 1 year of follow-up. In 2005, Keane ${ }^{106}$ summarized 33 years of his clinical experience with INO and also noted approximately one-third of cases to be from stroke and one-third from MS. Although $87 \%$ of the stroke cases were unilateral, bilateral disease was more suggestive of MS.

About one-quarter of MS patients suffer from clinically diagnosed unilateral or bilateral INO. ${ }^{102,107}$ Symptoms may include blurred vision, diplopia, oscillopsia, loss of stereopsis, and reading fatigue. Convergence typically remains intact. Physician detection of INO is accurate in severe cases with decreased range of adduction, but in mild to moderate cases, only the velocity of adduction may be affected, and the diagnosis is often missed. ${ }^{108}$ In these patients, the use of infrared oculography may reveal the adduction deficit. ${ }^{108-110}$ Thus, the prevalence of INO in MS patients is likely underestimated.

Nystagmus of the contralateral eye may be an adaptive process to compensate for the break in binocular fusion with the weak or slow adduction of the ipsilateral eye. ${ }^{111-113}$ Other findings which may be associated with an INO include slowing of abduction, disturbance in vertical eye movement, and skew deviation. ${ }^{113}$ Slowing of abduction in the ipsilateral eye has been reported, particularly in cases of significant ophthalmoparesis and large MRI lesions, and it is thought to be related to defective relaxation of the dysfunctioning antagonist medial rectus. ${ }^{104,113-115}$ Vertical eye movement disorders are associated with bilateral INO. The MLF carries the 
Table 3 Common efferent neuro-ophthalmologic disorders in MS

\begin{tabular}{|c|c|c|c|c|c|}
\hline Abnormality & Frequency $^{\mathbf{a}}$ & Localization & Features & Treatment & References \\
\hline INO & $60 \%-68 \%$ & $\begin{array}{l}\text { MLF (Dorsomedial } \\
\text { pontine or midbrain } \\
\text { tegmentum) }\end{array}$ & $\begin{array}{l}\text { Limited or slow } \\
\text { adduction in ipsilateral } \\
\text { eye on horizontal } \\
\text { saccadic eye movements; } \\
\text { horizontal nystagmus in } \\
\text { contralateral eye }\end{array}$ & Steroids acutely & $88,103-118$ \\
\hline Saccadic dysmetria & $80 \%-91 \%$ & Cerebellum, brainstem & $\begin{array}{l}\text { Overshoots, } \\
\text { undershoots, directional } \\
\text { dysmetria, ipsipulsion, } \\
\text { contrapulsion }\end{array}$ & Steroids acutely & $\begin{array}{l}102-103,105 \\
119\end{array}$ \\
\hline Nystagmus & $\begin{array}{l}36 \%-65 \% \text { (gaze-evoked) } \\
10 \%-18 \% \text { (pendular and } \\
\text { downbeat in central } \\
\text { position) }\end{array}$ & $\begin{array}{l}\text { Cerebellum, brainstem, } \\
\text { vestibular apparatus }\end{array}$ & $\begin{array}{l}\text { Gaze-evoked, pendular, } \\
\text { upbeat, downbeat, } \\
\text { multidirectional, rebound, } \\
\text { vestibular, periodic } \\
\text { alternating, occult (with } \\
\text { ophthalmoscopy) }\end{array}$ & $\begin{array}{l}\text { Gabapentin, } \\
\text { memantine, baclofen, } \\
\text { clonazepam, 3,4- } \\
\text { diaminopyridine, } \\
\text { prisms, surgery }\end{array}$ & $\begin{array}{l}102-103 \\
124-143\end{array}$ \\
\hline Saccadic intrusions & $\mathrm{n} / \mathrm{a}$ & $\begin{array}{l}\text { Brainstem (pause cell } \\
\text { neurons), cerebellum }\end{array}$ & $\begin{array}{l}\text { Inappropriate saccades } \\
\text { including square-wave } \\
\text { jerks, macro square-wave } \\
\text { jerks, macrosaccadic } \\
\text { oscillations, ocular } \\
\text { flutter, opsoclonus, and } \\
\text { microsaccadic flutter }\end{array}$ & $\begin{array}{l}\text { Baclofen, } \\
\text { anticonvulsants, } \\
\text { memantine? }\end{array}$ & $88,105,120-123$ \\
\hline $\begin{array}{l}\text { Smooth pursuit } \\
\text { impairment }\end{array}$ & $31 \%-75 \%$ & $\begin{array}{l}\text { Higher cortical pursuit } \\
\text { system (parietal- } \\
\text { occipital-temporal } \\
\text { junction) }\end{array}$ & $\begin{array}{l}\text { Inability to maintain } \\
\text { conjugate fixation on } \\
\text { a moving target }\end{array}$ & None & $102-103,145$ \\
\hline VOR impairment & $36 \%-55 \%(75 \%)^{b}$ & Flocculus & $\begin{array}{l}\text { Inability to suppress } \\
\text { the VOR; characteristic } \\
\text { catch-up saccades when } \\
\text { trying to fixate on } \\
\text { a target moving with the } \\
\text { head }\end{array}$ & None & $\begin{array}{l}102-103,105 \\
146,147\end{array}$ \\
\hline
\end{tabular}

Notes: aln MS patients with abnormal eye movements; ${ }^{102,103} \mathrm{bln}$ a study of 20 patients with MS. ${ }^{146}$

Abbreviations: MS, multiple sclerosis; MLF, medial longitudinal fasciculus; INO, internuclear ophthalmoparesis; VOR, vestibular ocular reflex.

myelinated fibers of the vertical pursuit, vertical vestibular, and otolithic-mediated ocular movement pathways. Patients with bilateral INO present with vertical and torsional nystagmus, characteristic of vertical gaze-holding and vertical VOR abnormalities, and altered optokinetic and pursuit responses. ${ }^{104,116,117}$ Skew deviation and supranuclear vertical ocular misalignment with binocular torsional deficits can occur with an INO. The higher eye is usually on the side of the MLF lesion. ${ }^{87,104,113}$

\section{Disorders of fixation}

Saccadic dysmetria, saccadic intrusions, and nystagmus are disorders of fixation seen in MS patients. Saccadic dysmetria is present in most of the MS patients with abnormal eye movements. ${ }^{101,102}$ Patients may exhibit overshoots (hypermetria), undershoots (hypometria), or directional dysmetria (vertical movements in a horizontal saccade). Lesions in the cerebellar vermis and posterior fastigial nuclei affect sac- cadic accuracy. Hypometria may occur if the vermis alone is affected, and hypermetria may occur if deep nuclei are involved. ${ }^{104,118}$

Saccadic intrusions include square-wave jerks, inappropriate sudden movements away from and back to a point of fixation. There is an intersaccadic latency between these events. Macro square-wave jerks are similar to and fro intrusions but are larger in amplitude. Ocular flutter and opsoclonus are saccadic intrusions without interval latency. The former is characterized by back to back horizontal saccades, and the latter involves horizontal, vertical, and torsional saccades. ${ }^{119}$ Microsaccadic flutter similarly has no intersaccadic latency, and when patients may report shimmering or wavy vision, ophthalmoscopy or eye-movement recordings are often required to make this rare diagnosis. ${ }^{120}$ Saccadic intrusions result from lesions in the cerebellum and brainstem; pause cell (located in the pontine raphe) dysfunction has been implicated, and these disorders may 
respond to anticonvulsants or baclofen. ${ }^{87,104,120}$ For various etiologies, a number of other agents have been tried, including methylphenidate, IV immunoglobulin, and clonazepam. ${ }^{121}$ Memantine has also been used to improve saccadic intrusion frequency in 2 patients with hereditary ataxia. ${ }^{122}$

Dysfunction of gaze-holding mechanisms in the brainstem and cerebellum may lead to the drifting of the eyes away from a target followed by involuntary corrective saccades, defined as nystagmus. When symptomatic, the patient often experiences visual dysfunction and oscillopsia, a skipping of the visual environment. Many types of nystagmus may be seen in MS. Gaze-evoked nystagmus is seen in roughly one-third of MS patients and may be caused by lesions in the medial vestibular nucleus, nucleus prepositus hypoglossi, and flocculus. ${ }^{101,102,123}$ Pendular nystagmus, oscillations in which there is equal velocity in both directions, also occurs often relatively and can interfere with visual function. ${ }^{101,102,123-127}$ Other forms of nystagmus reported in MS include upbeat, downbeat, rebound, multidirectional, periodic alternating, see-saw, dissociated, and vestibular. ${ }^{101,102,104,128-131}$ Small studies have demonstrated successful treatment for nystagmus with baclofen, gabapentin, memantine, clonazepam, 3,4-diaminopyridine, fampridine, prisms, and surgery. ${ }^{104,121,128,132-143}$

\section{Other efferent disorders in MS}

A variety of other efferent syndromes may be present in MS patients depending on the location of demyelinating lesions. Impairment of smooth pursuit is common and likely related to the disruption of higher cortical centers, including the parieto-occipital-temporal junction. ${ }^{101,102,144}$ Patients with abnormal smooth pursuit also often demonstrate abnormal suppression of the VOR. ${ }^{104,145}$ They exhibit catch-up saccades on head impulse testing. ${ }^{104,146}$ Lesions in the abducens nucleus or the pontine paramedian reticular formation (PPRF) and the ipsilateral MLF cause one-and-a-half syndrome, in which there is an ipsilateral horizontal gaze palsy and an INO. ${ }^{144,147}$ Abduction of the contralateral eye is the only remaining horizontal eye movement.

Skew deviation is a vertical ocular misalignment and results from lesions in the pathways connecting the vestibular nuclei in the medulla to the third and fourth nuclei in the midbrain. ${ }^{144}$ If the lesion is in the lower brainstem, the contralateral eye is hypertropic. Lesions in the pons and midbrain cause ipsilateral hypertropia. Patients will report vertical diplopia. The ocular tilt reaction is a skew deviation combined with head tilt (away from hypertropic eye) and conjugate ocular torsion.
The dorsal midbrain (Parinaud) syndrome and nuclear and fascicular cranial nerve lesions can occur in MS. In the former, lesions to the posterior midbrain cause supranuclear upgaze paresis, pupillary light-near dissociation, convergence-retraction nystagmus, and eyelid retraction. ${ }^{144,148,149}$ Of the cranial nerve syndromes, sixth nerve paresis is the most common. ${ }^{150-152}$ Nuclear lesions produce an ipsilateral gaze paresis, whereas fascicular lesions cause an ipsilateral lateral rectus palsy. Various presentations of third nerve palsies including partial fascicular, upper or lower division, have been reported, ${ }^{150,153,154}$ whereas rare, isolated trochlear (fourth) nerve paresis has been described in MS. ${ }^{155}$

\section{Summary}

Demyelinating lesions in MS cause characteristic afferent and efferent visual syndromes. Detection of these syndromes during ophthalmologic evaluation may lead to early diagnosis and treatment and potentially better outcomes for these patients. Vision loss and ocular motility deficits are associated with overall disability, and these disorders may be an indication of disease severity.

Careful attention to the neuro-ophthalmologic findings in MS not only reveals information about current disease burden, but also offers discrete measures of structure and function in an accessible part of the nervous system amenable to research and the testing of current and future therapies for this disabling disease.

\section{Disclosure}

The authors report no conflicts of interest in this work.

\section{References}

1. Anderson DW, Ellenberg JH, Leventhal CM, Reingold SC, Rodriguez M, Silberberg DH. Revised estimate of the prevalence of multiple sclerosis in the United States. Ann Neurol. 1992;31:333-336.

2. Hirtz D, Thurman DJ, Gwinn-Hardy K, Mohamed M, Chaudhuri AR, Zalutsky R. How common are the "common" neurologic disorders? Neurology. 2007;68:326-337.

3. Poser CM. Prevalence of multiple sclerosis. Ann Neurol. 1992;32: 716-717; author reply 718-719.

4. Poser CM, Brinar VV. The accuracy of prevalence rates of multiple sclerosis: a critical review. Neuroepidemiology. 2007;29:150-155.

5. Whetten-Goldstein K, Sloan FA, Goldstein LB, Kulas ED. A comprehensive assessment of the cost of multiple sclerosis in the United States. Mult Scler. 1998;4:419-425.

6. Arnold AC. Evolving management of optic neuritis and multiple sclerosis. Am J Ophthalmol. 2005;139:1101-1108.

7. Baier ML, Cutter GR, Rudick RA, et al. Low-contrast letter acuity testing captures visual dysfunction in patients with multiple sclerosis. Neurology. 2005;64:992-995.

8. Balcer LJ, Baier ML, Pelak VS, et al. New low-contrast vision charts: reliability and test characteristics in patients with multiple sclerosis. Mult Scler. 2000;6:163-171.

9. Fisher JB, Jacobs DA, Markowitz CE, et al. Relation of visual function to retinal nerve fiber layer thickness in multiple sclerosis. Ophthalmology. 2006;113:324-332. 
10. Zaveri MS, Conger A, Salter A, et al. Retinal imaging by laser polarimetry and optical coherence tomography evidence of axonal degeneration in multiple sclerosis. Arch Neurol. 2008;65:924-928.

11. Talman LS, Bisker ER, Sackel DJ, et al. Longitudinal study of vision and retinal nerve fiber layer thickness in mulitple sclerosis. Ann Neurol. 2010;67:749-760.

12. Kolappan M, Henderson AP, Jenkins TM, et al. Assessing structure and function of the afferent visual pathway in multiple sclerosis and associated optic neuritis. J Neurol. 2009;256:305-319.

13. Optic Neuritis Study Group. The clinical profile of optic neuritis Experience of the Optic Neuritis Treatment Trial. Arch Ophthalmol. 1991;109:1673-1678.

14. Beck RW. The Optic Neuritis Treatment Trial. Arch Ophthalmol. 1988;106:1051-1053.

15. Beck RW, Cleary PA, Anderson MM Jr, et al; The Optic Neuritis Study Group. A randomized, controlled trial of corticosteroids in the treatment of acute optic neuritis. N Engl J Med. 1992;326:581-588.

16. Cleary PA, Beck RW, Anderson MM Jr, Kenny DJ, Backlund JY, Gilbert PR. Design, methods, and conduct of the Optic Neuritis Treatment Trial. Control Clin Trials. 1993;14:123-142.

17. Beck RW, Cleary PA. Optic Neuritis Treatment Trial. One-year follow-up results. Arch Ophthalmol. 1993;111:773-775.

18. Beck RW. The optic Neuritis Treatment Trial: three-year follow-up results. Arch Ophthalmol. 1995;113:136-137.

19. Beck RW, Gal RL, Bhatti MT, et al. Visual function more than 10 years after optic neuritis: experience of the Optic Neuritis Treatment Trial. Am J Ophthalmol. 2004;137:77-83.

20. Hickman SJ, Dalton CM, Miller DH, Plant GT. Management of acute optic neuritis. Lancet. 2002;360:1953-1962.

21. Beck RW, Trobe JD, Moke PS, et al. High- and low-risk profiles for the development of multiple sclerosis within 10 years after optic neuritis: experience of the Optic Neuritis Treatment Trial. Arch Ophthalmol. 2003;121:944-949.

22. Optic Neuritis Study Group. The 5-year risk of MS after optic neuritis. Experience of the Optic Neuritis Treatment Trial. Neurology. 1997;49:1404-1413.

23. Hayreh SS. Anterior ischemic optic neuropathy. Clin Neurosci. 1997;4:251-263.

24. The Ischemic Optic Neuropathy Decompression Trial Research Group Optic nerve decompression surgery for nonarteritic anterior ischemic optic neuropathy (NAION) is not effective and may be harmful. JAMA. 1995;273:625-632.

25. Hazin R, Khan F, Bhatti MT. Neuromyelitis optica: current concepts and prospects for future management. Curr Opin Ophthalmol. 2009;20:434-439.

26. Jarius S, Paul F, Franciotta D, et al. Mechanisms of disease: aquaporin-4 antibodies in neuromyelitis optica. Nat Clin Pract Neurol. 2008;4:202-214.

27. Wingerchuk DM, Lennon VA, Lucchinetti CF, Pittock SJ, Weinshenker BG. The spectrum of neuromyelitis optica. Lancet Neurol. 2007;6:805-815.

28. Wingerchuk DM, Lennon VA, Pittock SJ, Lucchinetti CF, Weinshenker BG. Revised diagnostic criteria for neuromyelitis optica. Neurology. 2006;66:1485-1489

29. Petzold A, Pittock S, Lennon V, Maggiore C, Weinshenker BG, Plant GT. Neuromyelitis optica-IgG (aquaporin-4) autoantibodies in immune mediated optic neuritis. J Neurol Neurosurg Psychiatry. 2010;81:109-111.

30. Cabrera-Gómez JA, Bonnan M, González-Quevedo A, et al. Neuromyelitis optica positive antibodies confer a worse course in relapsingneuromyelitis optica in Cuba and French West Indies. Mult Scler. 2009;15:828-833.

31. McKeon A, Fryer JP, Apiwattanakul M, et al. Diagnosis of neuromyelitis spectrum disorders: comparative sensitivities and specificities of immunohistochemical and immunoprecipitation assays. Arch Neurol. 2009;66:1134-1138.

32. Merle H, Olindo S, Bonnan M, et al. Natural history of the visual impairment of relapsing neuromyelitis optica. Ophthalmology. 2007;114:810-815.
33. Weinshenker BG, Wingerchuk DM, Vukusic S, et al. NMO predicts relapse after longitudinally extensive transverse myelitis. Ann Neurol. 2006;59:566-569.

34. Matiello M, Lennon VA, Jacob A, et al. NMO-IgG predicts the outcome of recurrent optic neuritis. Neurology. 2008;70:2197-2200.

35. Bonnan M, Valentino R, Olindo S, Mehdaoui H, Smadja D, Cabre P. Plasma exchange in severe spinal attacks associated with neuromyelitis optica spectrum disorder. Mult Scler. 2009;15:487-492.

36. Mandler RN, Ahmed W, Dencoff JE. Devic's neuromyelitis optica: a prospective study of seven patients treated with prednisone and azathioprine. Neurology. 1998;51:1219-1220.

37. Jacob A, Matiello M, Weinshenker BG, et al. Treatment of neuromyelitis optica with mycophenolate mofetil: retrospective analysis of 24 patients. Arch Neurol. 2009;66:1128-1133.

38. Cree BA, Lamb S, Morgan K, Chen A, Waubant E, Genain C. An open label study of the effects of rituximab in neuromyelitis optica. Neurology. 2005;64:1270-1272.

39. Jacob A, Weinshenker BG, Violich I, et al. Treatment of neuromyelitis optica with rituximab: retrospective analysis of 25 patients. Arch Neurol. 2008;65:1443-1448.

40. Kidd D, Burton B, Plant GT, Graham EM. Chronic relapsing inflammatory optic neuropathy (CRION): a newly recognised steroid responsive syndrome seemingly distinct from sarcoidosis. Brain. 2003;126:276-284.

41. Trobe JD, Beck RW, Moke PS, Cleary PA. Contrast sensitivity and other vision tests in the Optic Neuritis Treatment Trial. Am J Ophthalmol. 1996;121:547-553.

42. Balcer LJ, Baier ML, Cohen JA, et al. Contrast letter acuity as a visual component for the multiple sclerosis functional composite. Neurology. 2003;61:1367-1373.

43. Klistorner A, Fraser C, Garrick R, Graham S, Arvind H. Correlation between full-field and multifocal VEPs in optic neuritis. Doc Ophthalmol. 2008;116:19-27.

44. Frederiksen JL, Petrera J. Serial visual evoked potentials in 90 untreated patients with acute optic neuritis. Surv Ophthalmol. 1999;44 Suppl 1: S54-S62.

45. Miller DH, Newton MR, van der Poel JC, et al. Magnetic resonance imaging of the optic nerve in optic neuritis. Neurology. 1988;38: $175-179$.

46. Hood DC, Odel JG, Winn BJ. The multifocal visual evoked potential. J Neuroophthalmol. 2003;23:279-289.

47. Fraser CL, Klistorner A, Graham SL, Garrick R, Billson FA, Grigg JR. Multifocal visual evoked potential analysis of inflammatory or demyelinating optic neuritis. Ophthalmology. 2006;113:323 e1-e2.

48. Rizzo JF 3rd, Andreoli CM, Rabinov JD. Use of magnetic resonance imaging to differentiate optic neuritis and nonarteritic anterior ischemic optic neuropathy. Ophthalmology. 2002;109:1679-1684.

49. Hickman SJ, Miszkiel KA, Plant GT, Miller DH. The optic nerve sheath on MRI in acute optic neuritis. Neuroradiology. 2005;47:51-55.

50. Dalton CM, Brex PA, Miszkiel KA, et al. Spinal cord MRI in clinically isolated optic neuritis. J Neurol Neurosurg Psychiatry. 2003;74: 1577-1580.

51. Morrissey SP, Miller DH, Kendall BE, et al. The significance of brain magnetic resonance imaging abnormalities at presentation with clinically isolated syndromes suggestive of multiple sclerosis. A 5-year follow-up study. Brain. 1993;116(Pt 1):135-146.

52. Hickman SJ. Optic nerve imaging in multiple sclerosis. J Neuroimaging. 2007;17 Suppl 1:S42-S45.

53. Jackson A, Sheppard S, Laitt RD, Kassner A, Moriarty D. Optic neuritis: MR imaging with combined fat-and water-suppression techniques. Radiology. 1998;206:57-63.

54. Kallenbach K, Frederiksen J. Optical coherence tomography in optic neuritis and multiple sclerosis: a review. Eur J Neurol. 2007;14:841-849.

55. Huang D, Swanson EA, Lin CP, et al. Optical coherence tomography. Science. 1991;254:1178-1181.

56. Hee MR, Izatt JA, Swanson EA, et al. Optical coherence tomography of the human retina. Arch Ophthalmol. 1995;113:325-332. 
57. Costello F, Coupland S, Hodge W, et al. Quantifying axonal loss after optic neuritis with optical coherence tomography. Ann Neurol. 2006;59: 963-969.

58. Costello F, Hodge W, Pan YI, Eggenberger E, Coupland S, Kardon RH. Tracking retinal nerve fiber layer loss after optic neuritis: a prospective study using optical coherence tomography. Mult Scler. 2008;14: 893-905.

59. Villoslada P, Sepulcre J, Toledo J, Bejarano B. Retinal nerve fiber layer is associated with brain atrophy in multiple sclerosis. Neurology. 2008;71:1747; author reply 1747-1748.

60. Gordon-Lipkin E, Chodkowski B, Reich DS, et al. Retinal nerve fiber layer is associated with brain atrophy in multiple sclerosis. Neurology. 2007;69:1603-1609.

61. Trip SA, Schlottmann PG, Jones SJ, et al. Retinal nerve fiber layer axonal loss and visual dysfunction in optic neuritis. Ann Neurol. 2005;58:383-391.

62. Beck RW, Cleary PA, Backlund JC. The course of visual recovery after optic neuritis. Experience of the Optic Neuritis Treatment Trial. Ophthalmology. 1994;101:1771-1778.

63. Beck RW, Cleary PA, Trobe JD, et al; The Optic Neuritis Study Group. The effect of corticosteroids for acute optic neuritis on the subsequent development of multiple sclerosis. $N$ Engl J Med. 1993; 329:1764-1769.

64. Wakakura M, Mashimo K, Oono S, et al; Optic Neuritis Treatment Trial Multicenter Cooperative Research Group (ONMRG). Multicenter clinical trial for evaluating methylprednisolone pulse treatment of idiopathic optic neuritis in Japan. Jpn J Ophthalmol. 1999;43:133-138.

65. Brusaferri F, Candelise L. Steroids for multiple sclerosis and optic neuritis: a meta-analysis of randomized controlled clinical trials. J Neurol. 2000;247:435-442.

66. The Optic Neuritis Study Group. Visual function 5 years after optic neuritis: experience of the Optic Neuritis Treatment Trial. Arch Ophthalmol. 1997;115:1545-1552.

67. Sellebjerg F, Nielsen HS, Frederiksen JL, Olesen J. A randomized, controlled trial of oral high-dose methylprednisolone in acute optic neuritis. Neurology. 1999;52:1479-1484.

68. Jacobs LD, Beck RW, Simon JH, et al; CHAMPS Study Group. Intramuscular interferon beta-1a therapy initiated during a first demyelinating event in multiple sclerosis. N Engl J Med. 2000;343:898-904.

69. Beck RW, Chandler DL, Cole SR, et al. Interferon beta-1a for early multiple sclerosis: CHAMPS trial subgroup analyses. Ann Neurol. 2002;51:481-490.

70. CHAMPS Study Group. Interferon beta-1a for optic neuritis patients at high risk for multiple sclerosis. Am J Ophthalmol. 2001;132: 463-471.

71. Kinkel RP, Kollman C, O'Connor P, et al. IM interferon beta-1a delays definite multiple sclerosis 5 years after a first demyelinating event. Neurology. 2006;66:678-684.

72. Comi G, Filippi M, Barkhof F, et al. Effect of early interferon treatment on conversion to definite multiple sclerosis: a randomised study. Lancet. 2001;357:1576-1582.

73. Kappos L, Polman CH, Freedman MS, et al. Treatment with interferon beta-1b delays conversion to clinically definite and McDonald MS in patients with clinically isolated syndromes. Neurology. 2006; 67:1242-1249.

74. Polman CH, Reingold SC, Edan G, et al. Diagnostic criteria for multiple sclerosis: 2005 revisions to the "McDonald Criteria". Ann Neurol. 2005; 58:840-846.

75. McDonald WI, Compston A, Edan G, et al. Recommended diagnostic criteria for multiple sclerosis: guidelines from the International Panel on the diagnosis of multiple sclerosis. Ann Neurol. 2001;50: 121-127.

76. Comi G, Martinelli V, Rodegher M, et al. Effect of glatiramer acetate on conversion to clinically definite multiple sclerosis in patients with clinically isolated syndrome (PreCISe study): a randomised, doubleblind, placebo-controlled trial. Lancet. 2009;374:1503-1511.
77. Pulicken M, Gordon-Lipkin E, Balcer LJ, Frohman E, Cutter G, Calabresi PA. Optical coherence tomography and disease subtype in multiple sclerosis. Neurology. 2007;69:2085-2092.

78. Siger M, Dziegielewski K, Jasek L, et al. Optical coherence tomography in multiple sclerosis: thickness of the retinal nerve fiber layer as a potential measure of axonal loss and brain atrophy. J Neurol. 2008;255:1555-1560.

79. Frohman EM, Dwyer MG, Frohman T, et al. Relationship of optic nerve and brain conventional and non-conventional MRI measures and retinal nerve fiber layer thickness, as assessed by OCT and GDx: a pilot study. J Neurol Sci. 2009;282:96-105.

80. Grazioli E, Zivadinov R, Weinstock-Guttman B, et al. Retinal nerve fiber layer thickness is associated with brain MRI outcomes in multiple sclerosis. J Neurol Sci. 2008;268:12-17.

81. Keltner JL, Johnson CA, Spurr JO, Beck RW; Optic Neuritis Study Group. Baseline visual field profile of optic neuritis. The experience of the Optic Neuritis Treatment Trial. Arch Ophthalmol. 1993;111:231-234.

82. Keltner JL, Johnson CA, Spurr JO, Beck RW. Visual field profile of optic neuritis. One-year follow-up in the Optic Neuritis Treatment Trial. Arch Ophthalmol. 1994;112:946-953.

83. Plant GT, Kermode AG, Turano G, et al. Symptomatic retrochiasmal lesions in multiple sclerosis: clinical features, visual evoked potentials, and magnetic resonance imaging. Neurology. 1992;42:68-76.

84. Biousse V, Trichet C, Bloch-Michel E, Roullet E. Multiple sclerosis associated with uveitis in two large clinic-based series. Neurology. 1999;52:179-181.

85. Newman NJ. Multiple sclerosis. In: Miller NR, Newman NJ, editors. Multiple Sclerosis. Baltimore: William and Wilkins; 1998: 5539-5676.

86. Zein G, Berta A, Foster CS. Multiple sclerosis-associated uveitis. Ocul Immunol Inflamm. 2004;12:137-142.

87. Chen L, Gordon LK. Ocular manifestations of multiple sclerosis. Curr Opin Ophthalmol. 2005;16:315-320.

88. Wiendl H, Hohlfeld R. Therapeutic approaches in multiple sclerosis: lessons from failed and interrupted treatment trials. BioDrugs. 2002; 16:183-200.

89. Gordon LK. Uveitis and neurological diseases. Br J Ophthalmol. 2004;88:1483-1484

90. Prieto JF, Dios E, Gutierrez JM, Mayo A, Calonge M, Herreras JM. Pars planitis: epidemiology, treatment, and association with multiple sclerosis. Ocul Immunol Inflamm. 2001;9:93-102.

91. Raja SC, Jabs DA, Dunn JP, et al. Pars planitis: clinical features and class II HLA associations. Ophthalmology. 1999;106:594-599.

92. Oruc S, Duffy BF, Mohanakumar T, Kaplan HJ. The association of HLA class II with pars planitis. Am J Ophthalmol. 2001;131:657-659.

93. Malinowski SM, Pulido JS, Goeken NE, Brown CK, Folk JC. The association of HLA-B8, B51, DR2, and multiple sclerosis in pars planitis. Ophthalmology. 1993;100:1199-1205.

94. Arnold AC, Pepose JS, Hepler RS, Foos RY. Retinal periphlebitis and retinitis in multiple sclerosis. I. Pathologic characteristics. Ophthalmology. 1984;91:255-262.

95. Engell T. Neurological disease activity in multiple sclerosis patients with periphlebitis retinae. Acta Neurol Scand. 1986;73:168-172.

96. Tola MR, Granieri E, Casetta I, et al. Retinal periphlebitis in multiple sclerosis: a marker of disease activity? Eur Neurol. 1993;33:93-96.

97. Toussaint D. [Changes in the optic fundus in multiple sclerosis]. Bull Soc Belge Ophtalmol. 1982;199-200:235-256.

98. Adams CW, Poston RN, Buk SJ, Sidhu YS, Vipond H. Inflammatory vasculitis in multiple sclerosis. J Neurol Sci. 1985;69:269-283.

99. Engell T, Jensen OA, Klinken L. Periphlebitis retinae in multiple sclerosis. A histopathological study of two cases. Acta Ophthalmol (Copenh). 1985;63:83-88.

100. Hornsten G. The relation of retinal periphlebitis to multiple sclerosis and other neurological disorders. Acta Neurol Scand. $1971 ; 47: 413-425$. 
101. Downey DL, Stahl JS, Bhidayasiri R, et al. Saccadic and vestibular abnormalities in multiple sclerosis: sensitive clinical signs of brainstem and cerebellar involvement. Ann NY Acad Sci. 2002;956: 438-440.

102. Serra A, Derwenskus J, Downey DL, Leigh RJ. Role of eye movement examination and subjective visual vertical in clinical evaluation of multiple sclerosis. J Neurol. 2003;250:569-575.

103. Frohman EM, Zhang H, Kramer PD, et al. MRI characteristics of the MLF in MS patients with chronic internuclear ophthalmoparesis. Neurology. 2001;57:762-768.

104. Frohman EM, Frohman TC, Zee DS, McColl R, Galetta S. The neuro-ophthalmology of multiple sclerosis. Lancet Neurol. 2005;4: 111-121.

105. Bolanos I, Lozano D, Cantu C. Internuclear ophthalmoparesis: causes and long-term follow-up in 65 patients. Acta Neurol Scand. 2004; 110:161-165.

106. Keane JR. Internuclear ophthalmoparesis: unusual causes in 114 of 410 patients. Arch Neurol. 2005;62:714-717.

107. Tsuda H, Ishikawa H, Matsunaga H, Mizutani T. [A neuroophthalmological analysis in 80 cases of multiple sclerosis]. Rinsho Shinkeigaku. 2004;44:513-521.

108. Frohman TC, Frohman EM, O’Suilleabhain P, et al. Accuracy of clinical detection of INO in MS: corroboration with quantitative infrared oculography. Neurology. 2003;61:848-850.

109. Frohman EM, Frohman TC, O'Suilleabhain P, et al. Quantitative oculographic characterisation of internuclear ophthalmoparesis in multiple sclerosis: the versional dysconjugacy index Z score. J Neurol Neurosurg Psychiatry. 2002;73:51-55.

110. Frohman EM, O'Suilleabhain P, Dewey RB Jr, Frohman TC, Kramer PD. A new measure of dysconjugacy in INO: the first-pass amplitude. J Neurol Sci. 2003;210:65-71.

111. Zee DS, Hain TC, Carl JR. Abduction nystagmus in internuclear ophthalmoparesis. Ann Neurol. 1987;21:383-388.

112. Baloh RW,Yee RD, Honrubia V. Internuclearophthalmoparesis. I. Saccades and dissociated nystagmus. Arch Neurol. 1978;35: 484-489.

113. Zee DS. Internuclear ophthalmoparesis: pathophysiology and diagnosis. Baillieres Clin Neurol. 1992;1:455-470.

114. Bronstein AM, Rudge P, Gresty MA, Du Boulay G, Morris J. Abnormalities of horizontal gaze. Clinical, oculographic and magnetic resonance imaging findings. II. Gaze palsy and internuclear ophthalmoparesis. J Neurol Neurosurg Psychiatry. 1990; 53:200-207.

115. Kommerell G, Olivier D, Theopold H. Adaptive programming of phasic and tonic components in saccadic eye movements. Investigations of patients with abducens palsy. Invest Ophthalmol. 1976;15: 657-660.

116. Evinger LC, Fuchs AF, Baker R. Bilateral lesions of the medial longitudinal fasciculus in monkeys: effects on the horizontal and vertical components of voluntary and vestibular induced eye movements. Exp Brain Res. 1977;28:1-20.

117. Ranalli PJ, Sharpe JA. Vertical vestibulo-ocular reflex, smooth pursuit and eye-head tracking dysfunction in internuclear ophthalmoparesis. Brain. 1988;111(Pt 6):1299-1317.

118. Lewis RF, Zee DS. Ocular motor disorders associated with cerebellar lesions: pathophysiology and topical localization. Rev Neurol (Paris). 1993;149:665-677.

119. Leigh RJ, Zee DS. The Neurology of Eye Movements. 3rd ed. New York, NY: Oxford University Press; 1999.

120. Ashe J, Hain TC, Zee DS, Schatz NJ. Microsaccadic flutter. Brain. 1991;114(Pt 1B):461-472.

121. Leigh RJ, Tomsak RL. Drug treatments for eye movement disorders. J Neurol Neurosurg Psychiatry. 2003;74:1-4.

122. Serra A, Liao K, Martinez-Conde S, Optican LM, Leigh RJ. Suppression of saccadic intrusions in hereditary ataxia by memantine. Neurology. 2008;70:810-812.

123. Liu GT, Volpe NJ, Galetta SL. Neuro-Opthalmology: Diagnosis and Management. 1st ed. Philadelphia, PA: WB Saunders Company; 2001.
124. Averbuch-Heller L, Zivotofsky AZ, Das VE, DiScenna AO, Leigh RJ. Investigations of the pathogenesis of acquired pendular nystagmus. Brain. 1995;118(Pt 2):369-378.

125. Lopez LI, Bronstein AM, Gresty MA, Du Boulay EP, Rudge P. Clinical and MRI correlates in 27 patients with acquired pendular nystagmus. Brain. 1996;119(Pt 2):465-472.

126. Barton JJ, Cox TA, Digre KB. Acquired convergence-evoked pendular nystagmus in multiple sclerosis. J Neuroophthalmol. 1999;19: 34-38.

127. Barton JJ, Cox TA. Acquired pendular nystagmus in multiple sclerosis: clinical observations and the role of optic neuropathy. $J$ Neurol Neurosurg Psychiatry. 1993;56:262-267.

128. Averbuch-Heller L. Acquired Nystagmus. Curr Treat Options Neurol. 1999;1:68-73.

129. Armstrong RA. Multiple sclerosis and the eye. Ophthalmic Physiol Opt. 1999;19 Suppl 2:S32-S42.

130. Sandramouli S, Benamer HT, Mantle M, Chavan R. See-saw nystagmus as the presenting sign in multiple sclerosis. J Neuroophthalmol. 2005; 25:56-57.

131. Matsumoto S, Ohyagi Y, Inoue I, et al. Periodic alternating nystagmus in a patient with MS. Neurology. 2001;56:276-277.

132. Strupp M, Schuler O, Krafczyk S, et al. Treatment of downbeat nystagmus with 3,4-diaminopyridine: a placebo-controlled study. Neurology. 2003;61:165-170.

133. Kalla R, Glasauer S, Schautzer F, et al. 4-Aminopyridine improves downbeat nystagmus, smooth pursuit, and VOR gain. Neurology. 2004;62:1228-1229.

134. Averbuch-Heller L, Tusa RJ, Fuhry L, et al. A double-blind controlled study of gabapentin and baclofen as treatment for acquired nystagmus. Ann Neurol. 1997;41:818-825.

135. Jain S, Proudlock F, Constantinescu CS, Gottlob I. Combined pharmacologic and surgical approach to acquired nystagmus due to multiple sclerosis. Am J Ophthalmol. 2002;134:780-782.

136. Currie JN, Matsuo V. The use of clonazepam in the treatment of nystagmus-induced oscillopsia. Ophthalmology. 1986;93:924-932.

137. Young YH, Huang TW. Role of clonazepam in the treatment of idiopathic downbeat nystagmus. Laryngoscope. 2001;111:1490-1493.

138. Dieterich M, Straube A, Brandt T, Paulus W, Buttner U. The effects of baclofen and cholinergic drugs on upbeat and downbeat nystagmus. J Neurol Neurosurg Psychiatry. 1991;54:627-632.

139. Starck M, Albrecht H, Pollmann W, Straube A, Dieterich M. Drug therapy for acquired pendular nystagmus in multiple sclerosis. J Neurol. 1997;244:9-16.

140. Starck M, Albrecht H, Pollmann W, Dieterich M, Straube A. Acquired pendular nystagmus in multiple sclerosis: an examiner-blind cross-over treatment study of memantine and gabapentin. J Neurol. 2010;257(3):322-327.

141. Smith RM, Oommen BS, Stahl JS. Application of adaptive filters to visual testing and treatment in acquired pendular nystagmus. J Rehabil Res Dev. 2004;41:313-324.

142. Strupp M, Brandt T. Pharmacological advances in the treatment of neuro-otological and eye movement disorders. Curr Opin Neurol. 2006;19:33-40.

143. Wang Z, Dell'Osso LF, Zhang Z, Leigh RJ, Jacobs JB. Tenotomy does not affect saccadic velocities: suport for the "small-signal" gain hypothesis. Vision Res. 2006;46:2259-2267.

144. Balcer LJ. Anatomic review and topographic diagnosis. Ophthalmol Clin North Am. 2001;14:1-21, vii.

145. Sharpe JA, Goldberg HJ, Lo AW, Herishanu YO. Visual-vestibular interaction in multiple sclerosis. Neurology. 1981;31:427-433.

146. Niestroy A, Rucker JC, Leigh RJ. Neuro-ophthalmologic aspects of multiple sclerosis: using eye movements as a clinical and experimental tool. Clin Ophthalmol. 2007;1:267-272.

147. Wall M, Wray SH. The one-and-a-half syndrome - a unilateral disorder of the pontine tegmentum: a study of 20 cases and review of the literature. Neurology. 1983;33:971-980. 
148. Frohman EM, Dewey RB, Frohman TC. An unusual variant of the dorsal midbrain syndrome in MS: clinical characteristics and pathophysiologic mechanisms. Mult Scler. 2004;10:322-325.

149. Lee WB, Berger JR, O'Halloran HS. Parinaud syndrome heralding MS. Neurology. 2003;60:322.

150. Thomke F, Lensch E, Ringel K, Hopf HC. Isolated cranial nerve palsies in multiple sclerosis. J Neurol Neurosurg Psychiatry. 1997;63: 682-685.

151. Rush JA, Younge BR. Paralysis of cranial nerves III, IV, and VI. Cause and prognosis in 1,000 cases. Arch Ophthalmol. 1981;99:76-79.

152. Moster ML, Savino PJ, Sergott RC, Bosley TM, Schatz NJ. Isolated sixth-nerve palsies in younger adults. Arch Ophthalmol. 1984;102: $1328-1330$.
153. Ksiazek SM, Repka MX, Maguire A, et al. Divisional oculomotor nerve paresis caused by intrinsic brainstem disease. Ann Neurol. 1989;26:714-718.

154. Bentley PI, Kimber T, Schapira AH. Painful third nerve palsy in MS. Neurology. 2002;58:1532.

155. Jacobson DM, Moster ML, Eggenberger ER, Galetta SL, Liu GT. Isolated trochlear nerve palsy in patients with multiple sclerosis. Neurology. 1999;53:877-879.

156. Balcer LJ. Optic neuritis. N Engl J Med. 2006;354:1273-1280.

157. Burkholder BM, Galetta SL, Balcer LJ. Acute demyelinating optic neuritis. Expert Rev Ophthalmol. 2006;1:159-170.
Clinical Ophthalmology

\section{Publish your work in this journal}

Clinical Ophthalmology is an international, peer-reviewed journal covering all subspecialties within ophthalmology. Key topics include: Optometry; Visual science; Pharmacology and drug therapy in eye diseases; Basic Sciences; Primary and Secondary eye care; Patient Safety and Quality of Care Improvements. This journal is indexed on

\footnotetext{
Submit your manuscript here: http://www.dovepress.com/clinical-ophthalmology-journal
}

\section{Dovepress}

PubMed Central and CAS, and is the official journal of The Society of Clinical Ophthalmology (SCO). The manuscript management system is completely online and includes a very quick and fair peer-review system, which is all easy to use. Visit http://www.dovepress.com/ testimonials.php to read real quotes from published authors. 